\title{
Analytical methods for the determination of $\mathrm{Cr}^{6+}$ from fixed source emissions
}

https://doi.org/10.21698/rjeec.2020.223

Proceedings Paper

\section{MIHAELA PETRESCU, ELENA BUCUR, VALERIU DANCIULESCU*, ANDREEA COZEA, CLAUDIA-MIHAELA BORCESCU, MIHAI BRATU, GHEORGHITA TANASE}

National Research and Development Institute for Industrial Ecology - ECOIND, 71-73 Drumul Podul Dambovitei, 060652, Bucharest, Romania

*Corresponding author (e-mail): validanciulescu@yahoo.com

\section{Abstract}

This study aimed to develop two analytical methods for the determination of $\mathrm{Cr}^{6+}$ from fixed source emissions, such as the molecular absorption spectrophotometric method (UV-VIS) and the graphite furnace atomization absorption spectrometry method (GTAAS). The first stage in the development of analytical methods involves establishing the optimal operating conditions for, taking air samples, treating them for analysis, and the proceeding for analysis, followed by validating the method by determining performance parameters. For both methods is highly recommended, the use of isokinetic sampling with a sampling probe by the heated glass, quartz, or PTFE. The limit of detection and the limit of quantification were concluded to be $12.38 \mu \mathrm{g} / \mathrm{m}^{3}$ and $40 \mu \mathrm{g} / \mathrm{m}^{3}$, respectively for the UV-VIS method and the GTAAS method $0.12 \mu \mathrm{g} / \mathrm{m}^{3}$ and $0.54 \mu \mathrm{g} / \mathrm{m}^{3}$ respectively.

Keywords: isokinetic sampling, fixed source emissions, UV-Vis, GTAAS

\section{INTRODUCTION}

Given the toxicity of the $\mathrm{Cr}^{6+}$ compounds in recent years, several studies have been developed to identify and quantify them in the environment. Given its carcinogenic, mutagenic character, with particularly strong effects on the human body, there is a tendency to identify substitutes of $\mathrm{Cr}^{6+}$ compounds in technological processes, where possible, or, where they cannot be replaced, conditions are imposed such us strict emission monitoring and emission limit values as low as possible. Exposure to hexavalent chromium compounds can cause skin allergies, dermatitis, and ulcers, perforation of the nasal septum, and bronchial carcinomas [1-3].
In a few situations $\mathrm{Cr}^{6+}$ is found only in this form in environmental factors, most of the time in the matrix we have met a mixture of chromium compounds in the oxidation state III and VI. The determination of $\mathrm{Cr}^{6+}$ from environmental factors, therefore, suppose, first of all, a species of the two forms of chromium, $\mathrm{Cr}^{6+}$ and $\mathrm{Cr}^{3+}$ [4-6]. The best-known method of species is based on the reaction of $\mathrm{Cr}^{6+}$ with $1,5-$ diphenylcarbazide (DPC) in a strongly acidic environment (Fig.1) with the formation of a complex combination of $\mathrm{Cr}^{3+}$ with 1,5diphenylcarbazone of red-purple colour whose intensity that is directly proportional to the $\mathrm{Cr}^{6+}$ concentration [7].
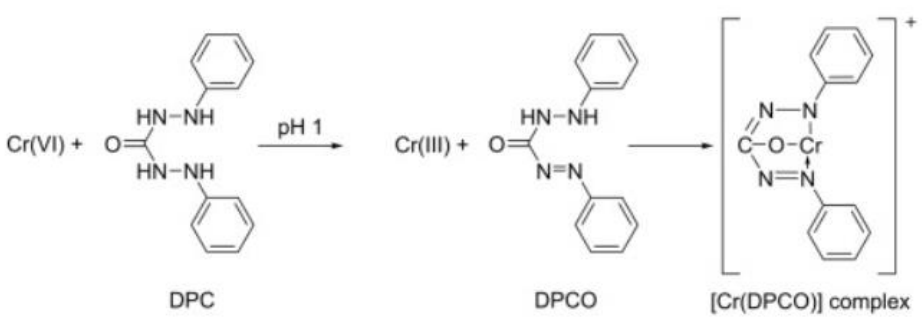

Fig. 1. The reaction of 1,5-diphenylcarbazide (DPC) with $\mathrm{Cr}^{6+}$

In the main, the methods for determining hexavalent chromium are divided into two categories [8-10]:
- chromatographic methods are based on liquid chromatography coupled with specific detectors. They have the advantage that they require a simple pre-treatment of the sample, 
they are fast but they need high-performance equipment that will be not always available.

- non-chromatographic methods that first involve a sample separation procedure, such as solid-phase extraction or liquid-liquid extraction. The most commonly used techniques are Spectrometric techniques. These methods are more time spending but are less expensive and easy to apply in a routine lab activity.

The development of one method for the determination of $\mathrm{Cr}^{6+}$ from the emissions of fixed sources implies the establishment of the optimal sampling conditions, sample preparation, and analytical quantification but also the validation of the method by determining the performance parameters and verifying the adequacy for the purpose. A variety of spectrophotometric and colorimetric techniques has been designed to determine $\mathrm{Cr}^{6+}$

\section{MATERIALS AND METHODS}

\section{Equipment}

The experiments for establishing the optimal conditions for the analysis of hexavalent chromium by UV-VIS technique were performed using a CINTRA 5 UV-VIS spectrophotometer by GBC Scientific Equipment Pty Ltd. Cintra 5 UV-VIS spectrophotometer with double beam covering a wide spectral range, from 190-1100 nm. For pH measurement, we used Multiparameter model

\section{Reagents}

Reagents and chemicals used in this study were of analytical grade. All glassware used was decontaminated by soaking it in $10 \%(\mathrm{v} / \mathrm{v})$ $\mathrm{HNO}_{3}$ solution for 24 hours and rinsed with ultrapure water. Ultra Clear TWF UV water purification system, Manufacturer SIEMENS (SG WATER) -Germany was used to obtain ultrapure water. Sodium hydroxide (97\%, Sigma Aldrich), $0.1 \mathrm{M} \quad \mathrm{NaOH}$ absorbent solution; 1,5-diphenylcarbazide reagent
[11-14]. The most common colorimetric method uses the selective reaction of $\mathrm{Cr}^{6+}$ with 1,5-diphenylcarbazone complex. Compared to the trivalent form, hexavalent chromium is considered an extremely dangerous metal due to its oxidizing, mutagenic, and carcinogenic properties. $\mathrm{Cr}^{6+}$ compounds are approximately 1,000 times more cytotoxic and mutagenic than $\mathrm{Cr}^{3+}[15-17]$.

This study aimed to develop two analytical methods for the determination of $\mathrm{Cr}^{6+}$ from fixed source emissions, respectively the molecular absorption spectrophotometric method (UV-VIS) and the graphite furnace atomization absorption spectrometry method (GTAAS).

For both methods is highly recommended, the use of isokinetic sampling with a sampling probe by the heated glass, quartz, or PTFE.

Seven Excellence, METLLER TOLEDO AG SWITZERLAND with $\mathrm{pH}$ electrode InLab Expert Pro-ISM. The experiments for establishing the optimal conditions for the analysis of hexavalent chromium by GTAAS technique were performed using an AAS FS 280 spectrometer, by-VARIAN equipped with graphite oven type GTA 120 and autosamplerdispenser PSD 120.

( $\geq 98,0 \%$, Sigma Aldrich), $0.5 \%$ solution (w/v) DPC was dissolved in acetone (freshly prepared); Sulfuric acid (96\%, ultrapure, ChemLab), $5 \mathrm{M} \quad \mathrm{H}_{2} \mathrm{SO}_{4}$ solution; Sodium chloride, saturated solution, $300 \mathrm{~g} / \mathrm{L} \mathrm{NaCl}$, (99.99\%, Merck); Isoamyl alcohol ( $\geq 99.0 \%$, Sigma Aldrich); A standard solution of $1000 \mathrm{mg} / \mathrm{L} \mathrm{Cr}^{6+}$ (Sigma-Aldrich) was used to calibrate the method.

\section{Sampling}

For both methods, the sampling conditions were the same: isokinetic sampling with heated glass, quartz or teflon sampling probe, and retaining $\mathrm{Cr}^{6+}$ in an absorbent solution containing a $0.1 \mathrm{M}$ $\mathrm{NaOH}$.

In figure 2 it is the sampling system [18] that it was used for UV-VIS and GTAAS verification methods of real samples. In the time of sampling, it was paid attention in maintaining and 
verification of $\mathrm{pH}$ absorbent solution, more than 8.5 for the reason of reduction of $\mathrm{Cr}^{6+}$ to $\mathrm{Cr}^{3+}, \mathrm{a}$ case that invalidated the samples.

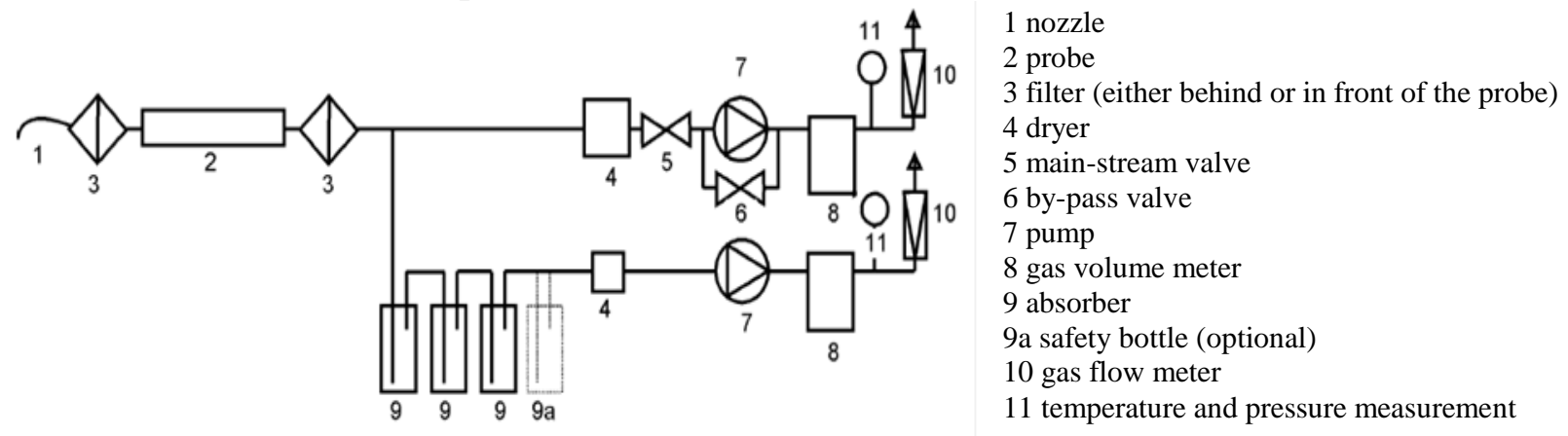

Fig. 2. Schematic of an isokinetic system for air sampling on the filter and absorbent solutions

The exposed absorbent solutions, after the $\mathrm{pH}$ checking, were taken quantitatively together with the washing solutions of the sampling system into a uniquely identified container (solution P1) and the filter is transported in a Petri dish in the laboratory extraction.

The sample preparation for analysis involves the same steps for both methods in the first phase of $\mathrm{Cr}^{6+}$ recovery from absorbent and filter solutions: extraction of water-soluble $\mathrm{Cr}^{6+}$ from the filter in P1 solution by stirring in the ultrasonic bath for 30 minutes, followed by filtration to remove any suspended particles and potential traces of precipitated $\mathrm{Cr}^{3+}$ and makeup to the mark with the absorbent solution (solution P2) in a dimensioned flask.

\section{RESULT AND DISCUSSION}

Determination of $\mathrm{Cr}^{6+}$ with $U V$-Vis spectrometry The determination of $\mathrm{Cr}^{6+}$ with UV-Vis spectrometry involved pipetting $35 \mathrm{~mL}$ of absorbent solution exposed into a $100 \mathrm{ml}$ beaker, adjusting the $\mathrm{pH}$ to $1.0 \pm 0.2$ with $6 \mathrm{~N}$ sulfuric acid followed by a quantitative collection of the solution into a $50 \mathrm{~mL}$ volumetric flask. It was added $1.0 \mathrm{~mL}$ of $1.5 \%$ diphenylcarbazide solution $0.5 \%$ in water, mixed and left to stand for 10 minutes untill developed colour. The absorbance was measured at a wavelength of $540 \mathrm{~nm}$ from the control sample using tanks with an optical path of $50 \mathrm{~mm}$.

The analytical parameters of the optimized method were: 1) the optimal wavelength, 2) the volume of 1,5 -diphenylcarbazide $0.5 \%$, and 3 ) the stability of the coloured complex. The results of the optimization tests are presented in Table 1.

Table 1. Test results to establish optimal operating conditions.

\begin{tabular}{|c|c|c|}
\hline $\begin{array}{l}\text { Optimized } \\
\text { parameter }\end{array}$ & Tests performed & $\begin{array}{c}\text { The optimal } \\
\text { value }\end{array}$ \\
\hline Wavelength & $\begin{array}{l}\text { Was drawn the spectrum for a series of solutions with } \\
\text { concentrations from } 0.5 \text { to } 3 \mu \mathrm{g} \mathrm{Cr}^{6+} / \text { volumetric flask, noting that } \\
\text { the wavelength corresponding to the maximum absorbance was } \\
540 \mathrm{~nm} \text {. }\end{array}$ & $540 \mathrm{~nm}$ \\
\hline $\begin{array}{c}\text { DPC volume } \\
0.5 \%\end{array}$ & $\begin{array}{l}\text { The volume of } 1,5 \text {-diphenylcarbazide solution was varied: } 0.5 \mathrm{ml} \text {; } \\
0.75 \mathrm{ml}, 1 \mathrm{ml} ; 1.5 \mathrm{ml} \text {, and } 2 \mathrm{ml} \text { keeping the other reagents constant, } \\
\text { and absorbance was measured for } \mathrm{Cr}^{6+} \text { concentrations between } 0.5 \\
\text { - } 3 \mu \mathrm{g} / \text { volumetric flask. It was observed that starting with } 0.75 \mathrm{ml} \\
\text { of soil. DPC } 0.5 \% \text { absorbance remains approximately constant. }\end{array}$ & $1 \mathrm{~mL}$ \\
\hline $\begin{array}{l}\text { Stability of the } \\
\text { complex }\end{array}$ & $\begin{array}{l}\text { The time variation of the absorbance of the solutions of } 1 \text { and } 3 \mu \mathrm{g} \\
\mathrm{Cr}^{6+} / \text { volumetric flask was registered; maximum absorbance is } \\
\text { obtained after } 10 \text { minutes and remains constant for } 2 \mathrm{~h} \text {. }\end{array}$ & $\begin{array}{c}2 \mathrm{~h} \\
\text { measurement }\end{array}$ \\
\hline
\end{tabular}


The working range for plotting the calibration curve was established by applying the $\mathrm{F}$ homogeneity test of concentration dispersions located at the extremes of the proposed working range $(0.5-3 \mu \mathrm{g} /$ volumetric flask) and the test results showed the lack of significant differences in dispersions at the working range, so the concentration range was $0.5-3$ $\mu \mathrm{g} /$ volumetric flask $\mathrm{Cr}^{6+}$ meets the requirements of the statistical test and can be used as a working range for the tested method.

Once the working range was established, the calibration curve was drawn in 6 points: $0.5 ; 1$; $1.52 ; 2.5$ and $3 \mu \mathrm{g} \mathrm{Cr} \mathrm{Cr}^{6+}$ volumetric flask inscribing on the ordinance of the absorbents and the abscissa the concentrations of the standards, in $\mu \mathrm{g}$ (Fig. 3). Calibration curve parameters validate the accuracy and precision of the method calibration (Table 2).

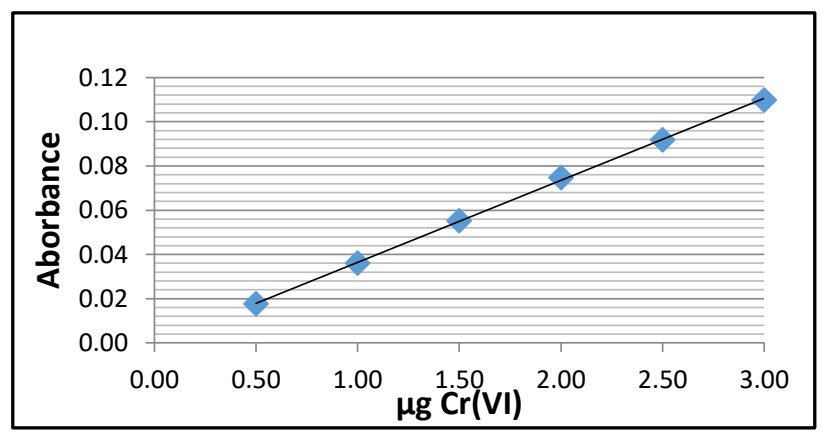

a

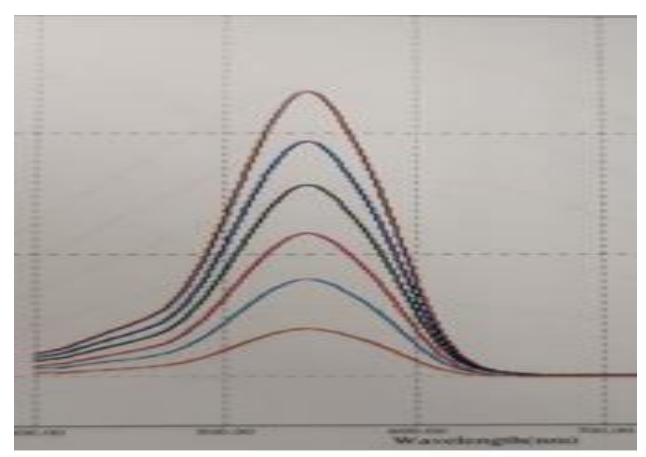

b

Fig. 3. a) Calibration curve on the range of 0.5-3 $\mu \mathrm{g} \mathrm{Cr}^{6+} /$ volumetric flask, b) Overlapping the spectral profiles of $\mathrm{Cr}^{6+}$ standard solutions obtained by the UV-VIS method

Table 2. Hexavalent chromium calibration data for the range $0.5-3 \mu \mathrm{g} \mathrm{Cr}^{6+} /$ volumetric flask

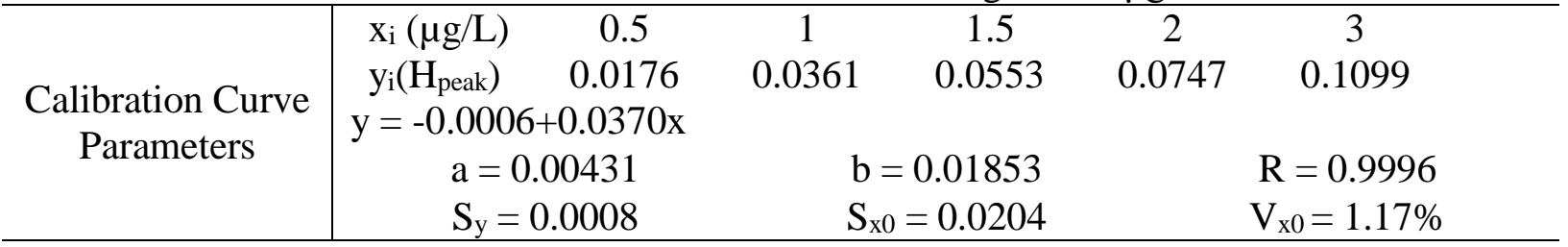

Determination of $\mathrm{Cr}^{6+}$ with electrothermal atomization (graphite furnace) - GTAAS method

$25 \mathrm{~mL}$ of the exposed sample was transferred in a $50 \mathrm{~mL}$ volumetric flask, adding $0.25 \mathrm{~mL}$ of $5 \mathrm{M} \mathrm{H}_{2} \mathrm{SO}_{4}$ solution and $1.00 \mathrm{~mL}$ of DPC $0.5 \%$ solution. The mixture was vortexed for 10 minutes to complete the reaction chain. Afterward, was added $20 \mathrm{~mL}$ of $\mathrm{NaCl}$ solution $(300 \mathrm{~g} / \mathrm{L})$ and $2.5 \mathrm{~mL}$ of isoamyl alcohol. The mixture was stirred for 5 minutes, followed by the liquid-liquid extraction. The organic solvent was transferred to the vial of the PSD 120 carousel and an amount of $10 \mu \mathrm{L}$ was injected into the graphite furnace. The pre-concentration factor of the method was 10. Figure 4 shows the steps taken to determine hexavalent chromium by the GTAAS method.

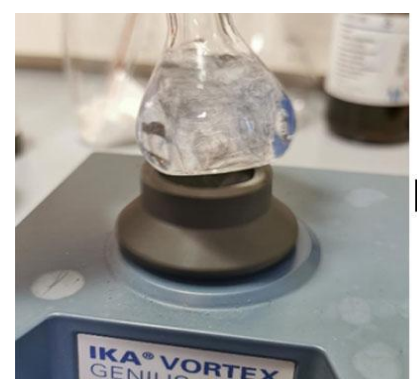

a)

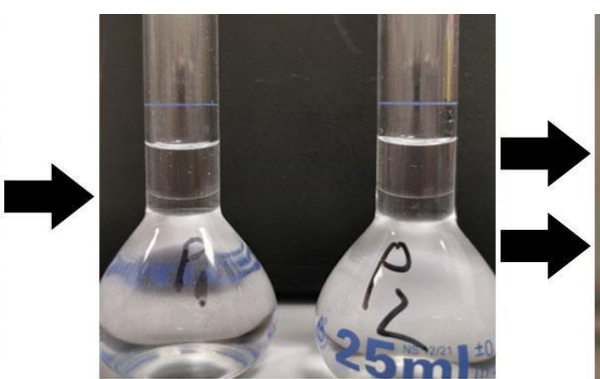

b)

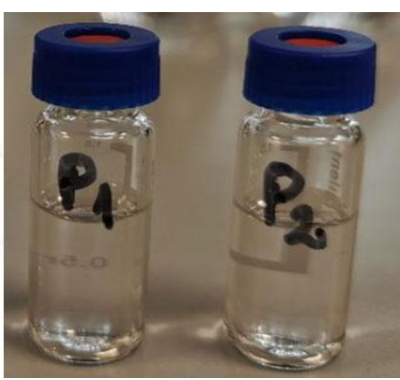

c)

Fig. 4. The steps are taken to determine hexavalent chromium by the GTAAS method: a) crom-1,5difenilcarbazona complex formation; b) isoamyl alcohol liquid-liquid extraction; c) extracts of $\mathrm{Cr}^{6+}$ 
Temperature program optimization. To obtain the best analytical results in graphite furnace atomic absorption spectrometry (GFAAS), it is necessary to optimize the furnace temperature program. This ensures the reduction of interferences due to the sample matrix without loss of the analyte. A temperature program for the graphite furnace analysis contains at least three basic steps: drying, calcination, and atomization. By selecting the optimum temperature and time, we obtain the highest analyte absorption signal and the lowest background noise signal. Spectral interferences that occur in the presence of anions or cations of iron or aluminum are associated with the optimization temperature $[19,20]$. Therefore, the optimization of the chromium temperature program is very important to eliminate or minimize both analytical losses and possible interferences. The highest signal was obtained when the atomization temperature was set at $2400^{\circ} \mathrm{C}$. The optimum drying, calcination, and atomization temperatures were $150^{\circ} \mathrm{C}, 1100^{\circ} \mathrm{C}$, and $2400^{\circ} \mathrm{C}$, respectively. The graphite tube was cleaned at a temperature of $2600^{\circ} \mathrm{C}$. The optimal flow rate of argon was $0.3 \mathrm{~L} / \mathrm{min}$ for the drying, calcination, and cleaning stages. Because the recommended wavelength for determining chromium is $357.9 \mathrm{~nm}$, it was not necessary to activate the background correction, this being used in the case of wavelengths with values lower than $350 \mathrm{~nm}$. It was also not necessary to use matrix modifiers because it was found that they do not bring any improvement to the method. To increase the signal-to-analyte to background-signal ratio, a graphite tube with a pyrolytic platform was used, recommended in the case of loaded matrices. Pyrolytic graphite has an additional advantage because the contamination from the sample is greatly reduced for most of the elements [21]. The tests for optimizing the temperature program and establishing the modifiers were performed with a solution of 6 $\mu \mathrm{g} / \mathrm{L} \mathrm{Cr}^{6+}$ in isoamyl alcohol. The setting for the GTAAS analysis is shown in Table 3.

Table 3. GFAAS instrumental parameters for the quantification of hexavalent chromium

\begin{tabular}{|c|c|c|c|c|}
\hline \multicolumn{5}{|c|}{ Parameters } \\
\hline \multirow{10}{*}{\multicolumn{3}{|c|}{$\begin{array}{c}\text { Calibration Mode } \\
\text { Measurement Mode } \\
\text { Replicates } \\
\text { Wavelength } \\
\text { Slit Width } \\
\text { Lamp Current, } \\
\text { Background Correction } \\
\text { Calibration Algorithm } \\
\text { Graphite tube type } \\
\text { Sample Volume } \\
\end{array}$}} & \multirow{10}{*}{\multicolumn{2}{|c|}{$\begin{array}{c}\text { Concentration } /\left(\mu \mathrm{L}^{-1}\right) \\
\text { Peak Height } \\
2 \\
357.9 \mathrm{~nm} \\
0.2 \mathrm{~nm} \\
7.0 \mathrm{~mA} \\
\text { BC Off } \\
\text { Linear } \\
\text { platform tubes, pyrolytic coated } \\
20 \mu \mathrm{L} \\
\end{array}$}} \\
\hline & & & & \\
\hline & & & & \\
\hline & & & & \\
\hline & & & & \\
\hline & & & & \\
\hline & & & & \\
\hline & & & & \\
\hline & & & & \\
\hline & & & & \\
\hline Step & Temperature $\left({ }^{0} \mathrm{C}\right)$ & Time (s) & Flow (L/min) & Gas Type \\
\hline 1 & 45 & 20 & 0.3 & Normal \\
\hline 2 & 90 & 25 & 0.3 & Normal \\
\hline 3 & 120 & 10 & 0.3 & Normal \\
\hline 4 & 150 & 5 & 0.3 & Normal \\
\hline 5 & 1000 & 10 & 0.3 & Normal \\
\hline 6 & 1000 & 5 & 0.3 & Normal \\
\hline 7 & 1100 & 0.7 & 0.0 & Normal \\
\hline 8 & 2400 & 0.8 & 0.0 & Normal \\
\hline 9 & 2400 & 2.5 & 0.0 & Normal \\
\hline 10 & 2600 & 2 & 0.3 & Normal \\
\hline 11 & 400 & 9.7 & 0.3 & Normal \\
\hline
\end{tabular}

Taking into account the special features of the matrix in which the analyte is found, isoamyl alcohol, as seen in Table 3, the increase in temperature on the drying stage was slower, increasing the time overtime to prevent losses due to rapid evaporation of alcohol and avoid ignition of its vapors. 
Calibration range. For the graphite furnace technique, it is necessary to prepare a bulk solution of known concentration, from which, with the help of the dispenser - autosampler system, the standard solutions are automatically prepared and injected to draw the calibration curve. For the method for determining hexavalent chromium, a calibration range consisting of five points was chosen, respectively $2 \mu \mathrm{g} / \mathrm{L}, 4 \mu \mathrm{g} / \mathrm{L}, 6 \mu \mathrm{g} / \mathrm{L}, 8 \mu \mathrm{g} / \mathrm{L}$, and
$10 \mu \mathrm{g} / \mathrm{L} \mathrm{Cr}{ }^{6+}$. The bulk was prepared at a concentration of $10 \mu \mathrm{g} / \mathrm{L} \mathrm{Cr}^{6+}$.

Using the pairs of values of hexavalent chromium concentration $\left(\mathrm{X}_{\mathrm{i}}\right)$ and absorbance $\left(\mathrm{Y}_{\mathrm{i}}\right)$ presented in Table 4, the calibration line was drawn by inscribing on the ordinance the absorbents of the standard samples, and on the abscissa the corresponding hexavalent chromium concentrations, in $\mu \mathrm{g} / \mathrm{LCr}^{6+}$.

Table 4. Hexavalent chromium calibration data for the range $2-10 \mu \mathrm{g} / \mathrm{L} \mathrm{Cr}^{6+}$

\begin{tabular}{c|cccccc}
\hline & $\mathrm{x}_{\mathrm{i}}(\mu \mathrm{g} / \mathrm{L})$ & 2 & 4 & 6 & 8 & 10 \\
Calibration Curve & $\mathrm{y}_{\mathrm{i}}\left(\mathrm{H}_{\text {peak }}\right)$ & 0.0415 & 0.0768 & 0.1144 & 0.1561 & 0.1880 \\
Parameters & $\mathrm{y}=0,00431+0,01853 \mathrm{x}$ & & & & \\
& $\mathrm{a}=0.00431$ & $\mathrm{~b}=0.01853$ & & $\mathrm{R}=0.9996$ \\
& $\mathrm{~S}_{\mathrm{y}}=0.0025$ & \multicolumn{2}{c}{$\mathrm{S}_{\mathrm{x} 0}=0.13406$} & $\mathrm{~V}_{\mathrm{x} 0}=2.23 \%$ \\
\hline
\end{tabular}

Using the SpectrAA software of the used equipment, the calibration curve for the hexavalent chromium presented in figure 5 was drawn, writing on the ordinance the absorbents of the standard samples, and on the abscissa the

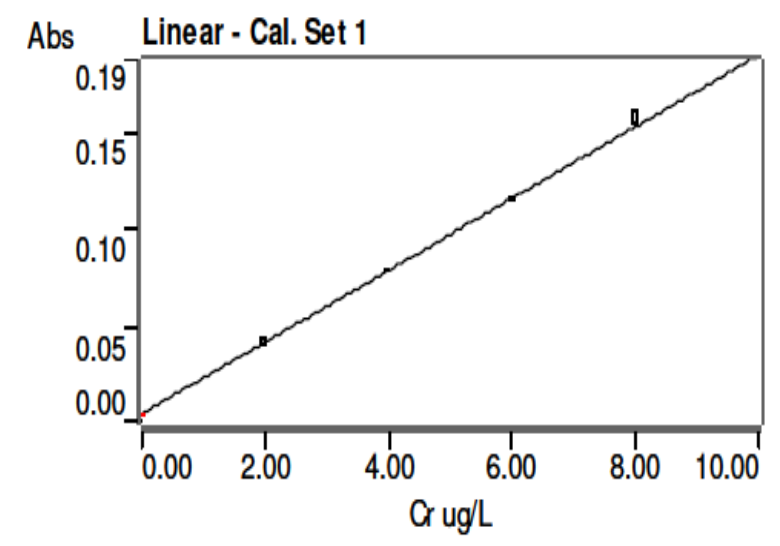

a) corresponding concentrations of hexavalent chromium, in $\mu \mathrm{g} / \mathrm{LCr}^{6+}$. Calibration curve parameters validate the accuracy and precision of the method calibration (Fig. 5).

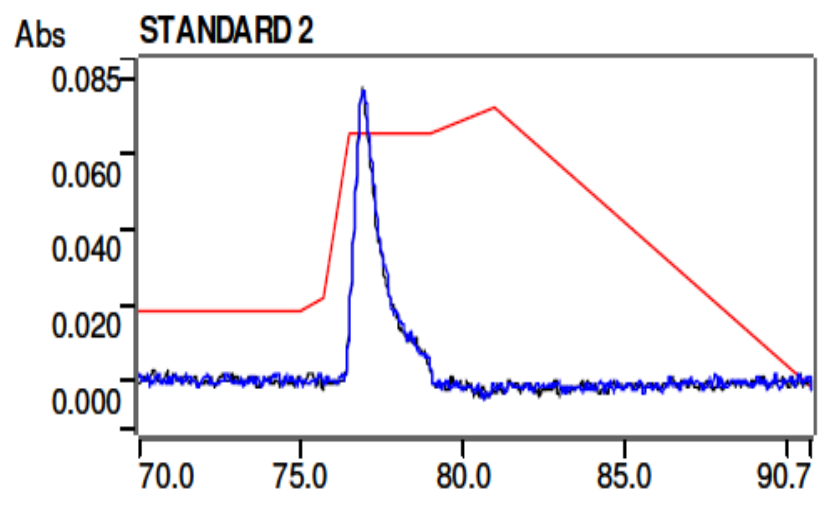

b)

Fig. 5. a) Calibration curve in the range $2-10 \mu \mathrm{g} / \mathrm{L} \mathrm{Cr}^{6+}$; b) the spectrum profile, $4 \mu \mathrm{g} / \mathrm{L} \mathrm{Cr}{ }^{6+}$

In-house methods validation for determining a $\mathrm{Cr}^{6+}$ source from fixed sourced emissions. The validation of the method is defined by a certain analytical requirement and the confirmation that the considered method should be capable of executing the required/imposed application [22, 23]. The objective of validating an analytical method is to demonstrate that it is suitable for the desired purpose. Both methods were subjected to validation and the values of the following performance and methodology parameters were determined: calibration range, linearity, Limit of Detection (LOD) and Limit of Quantification (LOQ), recovery accuracy, bias, repeatability, and measurement uncertainty. Table 5 shows the comparative parameters of the performance values for both methods.

The calculation of the performance parameters related to the volume of gaseous effluent sampled, in $\mu \mathrm{g} \mathrm{m}^{3}$, was performed in the following conditions: volume of gaseous effluent sampled: 60 1; solution volume P2: 200 $\mathrm{ml}$. 
Table 5. Parameter performance values of the determination methods of $\mathrm{Cr}^{6+}$ emissions

\begin{tabular}{l|cc}
\hline Parameters & Method UV-Vis & Method GTAAS \\
\hline Calibration range & $0.5 ; 1 ; 1,5 ; 2 ; 2.5 ; 3 \mu \mathrm{g} \mathrm{Cr}^{6+}$ & $2 ; 4 ; 6 ; 8 ; 10 \mu \mathrm{g} / \mathrm{L} \mathrm{Cr}^{6+}$ \\
Limit of Detection, LOD, $\left(\mu \mathrm{g} / \mathrm{m}^{3}\right)$ & 12.38 & 0.12 \\
Limit of Quantification , & 40 & 0.54 \\
LOQ, $\left(\mu \mathrm{g} / \mathrm{m}^{3}\right)$ & 1.78 & 9.22 \\
Repeatability, $\%$ & 5.3 & -16.84 \\
Bias, \% & 105.3 & 83.16 \\
Recovery, \% & 4.0 & 17.3 \\
Measurement uncertainty, \% & & \\
\hline
\end{tabular}

\section{CONCLUSIONS}

The analytical methods developed in its study allow us to determine the hexavalent chromium in the gaseous effluent from various industries. In the case of high hexavalent chromium emissions related to Electroplating and Anodizing industry, we recommend using the method of molecular absorption spectrophotometric method (UV-VIS).

In the case of glass factories or incinerators, we recommend the method of graphite furnace atomization absorption spectrometry method

\section{ACKNOWLEDGEMENTS}

The authors acknowledge the financial support offered by The National Research Program

\section{REFERENCES}

[1] JERABKOVA, J., TEJNECKY, V., BORUVKA, L., DRABEK, O. Sci. Agric. Bohem., 49, no. 4. 2018, p. 297.

[2] MILACIC, R., SCANCAR, J., 127, 2020, https://doi.org/10.1016/j.trac.2020.115888.

[3] KIM, J., SEO, S., KIM, Y., KIM, DH., Ann. Occup. Environ. Med., 30, 2018, p. 7.

[4] KIMBROUGH, D.E.; COHEN, Y.; WINER, A.M.; CREELMAN, L.; MABUNI, C. Crit. Rev. Environ. Sci. Technol., 29, 1999, p. 1.

[5].UNCETA, N., SEBY, F., MALHERBE, J., Anal. Bioanal. Chem., 397, 2010, p. 1097 https://doi.org/10.1007/s00216-009-3417-1.

[6] CROSLEY, E., Comparison of sample methods and results for hexavalent chromium exposures at LANGLEY AFB, Graduate Theses $\&$ Non-Theses. 86. Montana Tech, 2016. p. 146.

http://digitalcommons.mtech.edu/grad_rsch/86 [7] DUFFY, G., MAGUIRE, I., HEERY, B., GERS, P., DUCREE, J., REGAN, F., Talanta, 178, 2018, p. 392.
(GTAAS) whose sensitivity is much better.

Following the validation, the performance parameters of both methods fall within the acceptability criteria specific to the techniques used.

Based on the tests performed for the development and validation of the methods, we appreciate that both methods can be used to determine the $\mathrm{Cr}^{6+}$ concentration from the emissions of fixed sources.

“Nucleu” (PN 190402 02).

[8] KLATT, V., KUNZE, J., At. Spectrosc., 30, no. 6. 2009, p.185.

[9]. SPARKS, D.L., PAGE, A.L. HELMKE, P.A., LOEPPERT, R.H., SOLTANPOUR, P. N., TABATABAI, M. A., JOHNSTON, C. T., SUMNER, M. E., Methods of Soil Analysis: Part 3 Chemical Methods, 1996, p. 683-701. https://doi.org/10.2136/sssabookser5.3.c25.

[10].NAMIESNIK, J., RABAJCZYK, A., Crit. Rev. Environ. Sci. Technol., 42, no. 4, 2012, p. 327.

[11] NAFTI, M., CHAKROUN, R., HANNACHI, C., HAMROUNI, B., NOUAIGUI, H., Anal. Lett., 50, no. 12, 2017, p. 2012.

[12] LACE, A., RYAN, D., BOWKETT, M., CLEARY, J., Int. J. Environ. Res. Public Health, 16, 2019, p. 1803.

[13] BHATTACHARYA, A., GUPTA, A., KAUR, A., MALIK, D., Water Sci. Technol., 79, no. 3, 2019, p. 411. 
[14] PRAMANIK, S., DEY, S., [20] CHENA, H., DUA, P., CHEN, J., CHATTOPADHYAY. P., Anal. Chim. Acta, SHENGHUA, H, SHENGQING, L., 584, no. 2, 2007, p. 395.

[15] NARIN, I., KARS, A., SOYLAK, M., J. Hazard. Mater., 150, no. 2, 2008, p. 469.

[16] EZODDIN, M., SHEMIRANI, F., KHANI, R., DESALIN WATER TREAT, 262, no. 1-3, 2010, p 183.

[17] SAYGI, K., TUZEN, M., SOYLAK, M., ELCI, L., J. Hazard. Mater., 153, no. 3, 2008, p. 1009.

[18] EN 14385:2004: Stationary source emissions. Determination of the total emission of $\mathrm{As}, \mathrm{Cd}, \mathrm{Cr}, \mathrm{Co}, \mathrm{Cu}, \mathrm{Mn}, \mathrm{Ni}, \mathrm{Pb}, \mathrm{Sb}, \mathrm{Tl}$ and $\mathrm{V}$.

[19] GIL, R.A., CERUTTI, S., GASGUEZ, J,A, OLSINA, R.A., MARTINEZ, L.D., Talanta, 68, HANLAN, L., Talanta, 81, no. 1-2, 2010, p. 176.

[21] TUZEN, M., SOYLAK, M., J. Hazard. Mater., 129, no. 1-3, 2006, p. 266.

[22] TANASE, GH., RADU, G.L., PANA, A., BULEANDRA, M., Validation of analytical methods. Theoretical principles and case studies, Editura Printech, Bucharest, 2007, [in Romanian].

[23] ISO 8466-1:1990. Water quality. Calibration and evaluation of analytical methods and estimation of performance characteristics. Part I. Statistical evaluation the linear calibration function. no. 4 , p. 1065. 